\title{
REVIEW
}

\section{Role of substrate competition in the pathogenesis of insulin resistance in man}

\author{
Luc Tappy and Kevin Acheson ${ }^{1}$ \\ Institut de Physiologie, Faculté de Médecine, Université de Lausanne, Switzerland and ${ }^{1}$ Centre de Recherches Nestlé, Vers-chez-les-Blanc, \\ Lausanne, Switzerland \\ (Correspondence should be addressed to L Tappy, Institut de Physiologie, Rue du Bugnon 7, 1005 Lausanne, Switzerland)
}

\section{Introduction}

Carbohydrates, proteins and lipids share common metabolic pathways which may play important roles in the regulation of glucose metabolism. For the purpose of synthesis of energy-rich equivalents, catabolism of carbohydrates, lipids and several amino acids converge to yield acetyl coenzyme A (CoA) which will subsequently be oxidized in the tricarboxylic acid cycle. Other amino acids are converted to intermediate substrates of the same cycle. Oxidation of acetyl CoA is coupled to the synthesis of ATP and is therefore determined essentially by the rate of ADP formation from ATP or, in other words, by energy expenditure. Since acetyl CoA oxidation is pulled by the rate of ATP hydrolysis and cannot be pushed by substrate provision, excessive synthesis of acetyl CoA from one of the macro nutrients may subsequently interfere with the catabolism of other nutrients. Thus, from a theoretical point of view, an excess supply of lipids or amino acids may possibly interfere with glucose utilisation (Fig. 1). Most amino acids, the glycerol molecules released during hydrolysis of triglycerides and the lactate/pyruvate produced by non-oxidative glycolysis may also be reconverted to glucose in the gluconeogenic pathway. This is known to occur essentially in liver and kidney cells and it is currently estimated that it contributes to $30-60 \%$ of overall fasting glucose production (1-3).

Obesity is characterized by various degrees of whole body insulin resistance and hyperinsulinemia. Noninsulin dependent diabetes mellitus (NIDDM) is encountered with increased frequency in obese patients, indicating that this condition confers an increased risk for this disease (4). Alterations in the metabolism of lipids and proteins are also encountered in obese patients, due to changes in substrate intake and body composition. In particular, obese patients display increased rates of lipid oxidation and enhanced concentrations of free fatty acids in their blood. Tracer studies demonstrate that they have increased rates of glycerol and free fatty acid turnover, indicating increased lipolysis (5-7). Obese patients also have elevated protein turnover rates (8). This increased availability of lipid and amino acid substrates may possibly exert important effects on glucose metabolism which could contribute to insulin resistance. At the skeletal muscle and adipose cell level where insulin stimulates glucose oxidation, increased oxidation rates of other macro nutrients, driven by their increased blood concentrations, may interfere with glucose oxidation and hence its utilisation. At the level of the liver and kidneys, enhanced provision of glucose precursors may stimulate glucose synthesis and increase hepatic glucose production. The blood glucose concentration is controlled by the balance between the systemic delivery of glucose on the one hand, and glucose utilisation on the other. The former results from glycogenolysis and gluconeogenesis in liver and kidney cells, while the latter corresponds to glucose oxidation, which occurs at a constant rate in insulin-insensitive tissues (e.g. brain, kidney, medullae, etc.) and at variable rates according to insulin concentrations in insulinsensitive tissues (e.g. skeletal muscle, adipose cells, etc.), and glucose storage as glycogen. Insulin regulates blood glucose concentrations by modulating both glucose production and glucose utilisation.

\section{Effects of lipids on glucose utilisation}

It has been recognised for over 40 years that increased free fatty acid concentrations impede glucose utilisation in isolated skeletal or cardiac muscle (9). The mechanism postulated was that $\beta$-oxidation of free fatty acids was stimulated by their elevated concentrations leading to an enhanced formation of acetyl CoA, NADH and citrate. These substrates exert negative effects on the activities of the enzymes phosphofructokinase and pyruvate dehydrogenase, leading to inhibition of glycolysis and entrance of pyruvate into the tricarboxylic acid cycle. As a result of inhibition of glycolysis, glucose6-phosphate increases and the ensuing inhibition of hexokinase was put forward to explain a decrease in glucose transport into the cells (9). Since these early experiments, the interactions of fatty acids with basal and insulin-stimulated glucose utilisation have been extensively studied in human beings. It was observed that infusions of triglyceride emulsions, which increase plasma fatty acid concentrations and stimulate lipid oxidation, lead to an exaggerated plasma glucose response after ingestion of a glucose meal (10). Lipid 


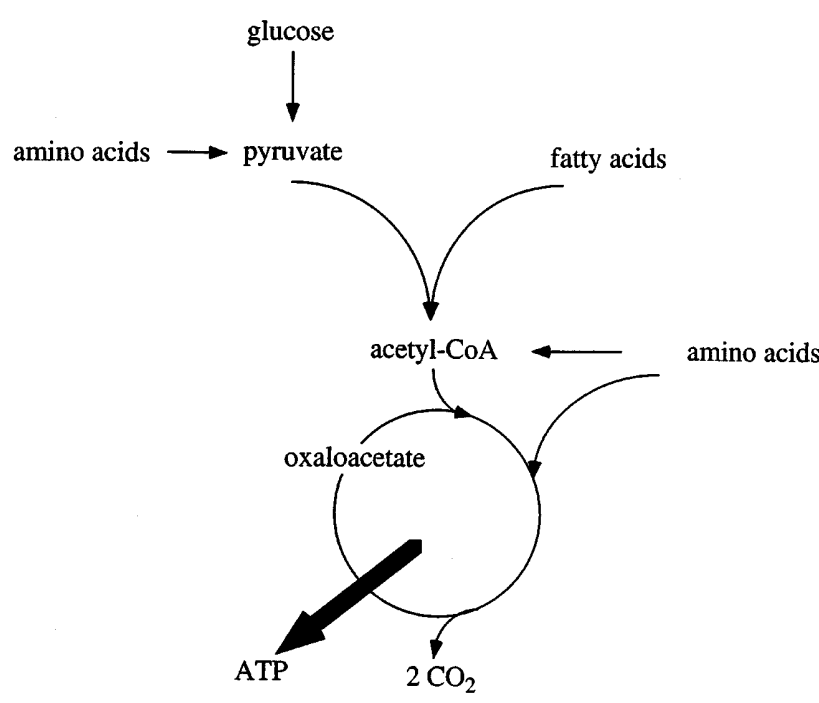

Figure 1 Interactions between major macro nutrients for their oxidation. Increased fatty acid concentrations are generally believed to stimulate their $\beta$ oxidation. The acetyl CoA generated is subsequently oxidized in the tricarboxylic acid cycle. The ensuing increase in acetyl CoA, citrate and NADH inhibits pyruvate conversion into acetyl CoA by inhibiting the pyruvate dehydrogenase complex, and thus decreases glucose oxidation. Several amino acids join the glucose metabolic pathway at the level of pyruvate or various intermediates of the tricarboxylic acid cycle. Since the rate of catabolism of acetyl CoA in the tricarboxylic acid cycle is limited by ATP demand (i.e. energy expenditure), an increased oxidation of any macro nutrient interferes with oxidation of the others unless energy expenditure is stimulated proportionally.

infusions were further observed to leave basal glucose utilisation unaffected, but to decrease insulin-mediated glucose utilisation as measured by the euglycemic, hyperinsulinemic clamp technique (11). During the same experimental procedure, it was observed that insulin-mediated glucose oxidation and glucose storage (presumably as glycogen synthesis in muscle) were both inhibited by lipids (12). A decrease in insulin-stimulated glycogen synthesis in skeletal muscle was confirmed by in vivo nuclear magnetic resonance spectroscopy (13). Recent work using fluoro-2-deoxyglucose and positron emission tomography scanning has demonstrated that inhibition of glucose utilisation takes place essentially in skeletal muscle (14).

The mechanisms by which lipids inhibit insulinmediated glucose utilisation appear to be more complex than initially proposed by Randle and collaborators, and may differ according to the duration of lipid infusions. According to the initial hypothesis of Randle (9), an increased supply of fatty acids should inhibit glucose oxidation and glycolysis and increase intracellular glucose-6-phosphate concentrations. Although most studies performed in healthy volunteers indicate that infusion of lipids decrease insulin-mediated glucose disposal (reviewed in (15)), the mechanisms responsible for this effect appear to differ from this initial hypothesis. Glycolysis measured by ${ }^{3} \mathrm{H}_{2} \mathrm{O}$ production during infusion of ${ }^{3} \mathrm{H}$-labeled glucose, was found to be decreased during lipid infusion (16). In contrast, isolated forearm studies indicated that forearm lactate production was increased during a euglycemic hyperinsulinemic clamp with lipid infusion (17); this latter observation suggested that lipid infusion did not inhibit glycolysis in skeletal muscle. Several studies have also assessed the effects of increased concentrations of free fatty acids on intramuscular glucose-6-phosphate concentrations, and have yielded partially contradictory results. It was observed, using in vivo nuclear magnetic resonance spectroscopy in healthy volunteers, that lipid infusion blunted the increase in muscle glucose-6-phosphate concentrations observed during a six-hour euglycemic-hyperinsulinemic clamp study (13). In another study, glucose-6-phosphate concentrations measured in muscle biopsies specimens were found to be decreased by lipid infusion during the first four hours of a similar hyperinsulinemic clamp, but to be increased during the next two hours $(16,18)$. Whole body insulin-mediated glucose utilisation was decreased during both periods. The authors suggested that free fatty acids interfered directly with the cellular glucose transport system in the early phase of their administration, while an inhibition of glucose utilisation beyond transport was postulated to account for the rise in glucose-6-phosphate during the late period of lipid infusion.

Obese patients generally have increased basal lipid oxidation rates and a blunted suppression of lipid oxidation during insulin administration. This suggests that lipid-glucose interactions may be responsible for the insulin resistance observed in these patients. In support of this hypothesis, it was found that inhibition of lipid oxidation by administration of antilipolytic agents improves glucose tolerance after a glucose meal (19), insulin-mediated glucose oxidation and glucose storage during euglycemic hyperinsulinemic clamps in obese patients (20). It was also observed that the glucose-fatty acid cycle was indeed operative in obese patients, i.e. that infusion of lipids in such patients also increased insulin resistance (21). These conclusions, however, have to be tempered for several reasons. It was recognised that administration of antilipolytic agents stimulate insulin-mediated glucose disposal, oxidation, and storage in lean non-insulin resistant subjects $(22,23)$. As a consequence, the apparent normalisation of glucose utilisation in obese patients treated with these agents may, in part, be artefactual. To our knowledge, no study comparing insulin sensitivity of obese and lean subjects treated with antilipolytic agents has been performed. In addition, it was recently reported that elevated plasma glucose concentrations may inhibit the cellular uptake of free fatty acids and their intracellular oxidation in NIDDM and obese patients (17).

The mechanisms by which glucose and free fatty acids compete for their metabolism remain unclear, but may be related to modulation of fatty acid binding 
proteins (24), which have been recognised as being involved in several aspects of fatty acid metabolism. In this regard, it was recently reported that mice with a null mutation in the gene coding for the adipocyte fatty acid binding protein aP2 are characterized by obesity without insulin resistance (25). These mice were also characterized by an absence of the increase in tumor necrosis factor-alpha expression (25) which is normally observed in the adipocytes of obese animals and which it has been suggested is involved in obesity-induced insulin resistance (26). This observation indicates that fatty acid binding proteins may possibly be responsible for some of the metabolic effects of increased free fatty acids, presumably by modulating gene expression.

\section{Effects of amino acids on glucose utilization}

The interactions of amino acids with glucose have been far less extensively studied than those of lipids. Infusions of mixtures of amino acids during euglycemic/ hyperinsulinemic clamps have led to contradictory results. Infusions of branched chain amino acids were shown to decrease whole body and forearm uptakes of glucose during hyperinsulinemic, euglycemic clamps (27). Infusions of mixtures of amino acids also decreased the rate of glucose infusion required to maintain euglycemia during insulin infusions (28, 29). This could, however, be largely explained by stimulation of endogenous glucose production which occurs during hyperaminoacidemia (Fig. 2). Glucose utilization monitored with $\left[{ }^{3} \mathrm{H}\right]$ glucose was, however, not affected by amino acid infusion (29). Furthermore, when basal glucagon concentrations were maintained in healthy subjects by infusions of somatostatin and glucagon, the rise in endogenous glucose production during amino acids infusion was totally prevented. In this condition, whole body insulin-mediated glucose disposal was similar with or without amino acids, indicating no major interaction between these two substrates for their oxidation (30).

The effect of amino acids on glucose oxidation is difficult to assess. Administration of amino acids increases urinary nitrogen excretion, indicating that they are actively catabolized. Net carbohydrate oxidation assessed by indirect calorimetry decreased when amino acids were infused during a hyperinsulinemic clamp (31). However, since gluconeogenesis is a major degradative pathway for amino acid oxidation, and since indirect calorimetry fails to compute oxidation of glucose formed from amino acid as carbohydrate oxidation (32), this method does not provide a faithful reflection of the actual rate of glucose oxidation by these tissues. To bypass the limitations of indirect calorimetry, the effects of amino acids on glucose oxidation were assessed in healthy volunteers using an isotope technique. With this technique, tracer amounts of ${ }^{13} \mathrm{C}$ labeled glucose are infused and ${ }^{13} \mathrm{CO}_{2}$ production is

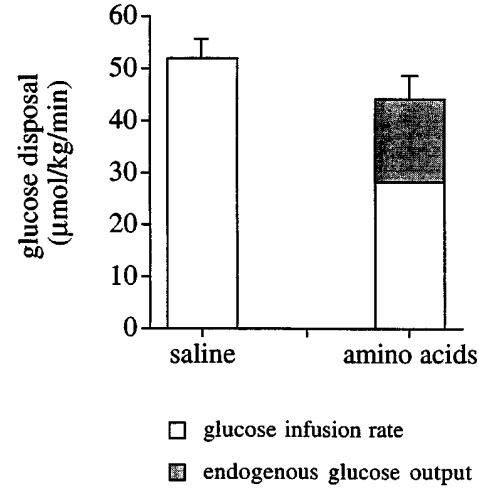

Figure 2 Effects of amino acids on glucose utilization and production during hyperinsulinemia. Healthy volunteers were studied during a euglycemic hyperinsulinemic (about $100 \mu \mathrm{U} / \mathrm{ml}$ ) clamp with infusion of saline or a mixture of amino acids, the latter at a rate of $0.5 \mathrm{~g} / \mathrm{kg} / \mathrm{h}$. Compared with saline, amino acids stimulated endogenous glucose production, and decreased the rate of exogenous glucose infusion required to maintain euglycemia. Total glucose utilization was, however, unaffected by amino acid infusion.

used to calculate oxidation of plasma glucose, including glucose produced from amino acids. Using this technique, it was observed in healthy volunteers that an infusion of a mixture of amino acids actually stimulated glucose oxidation. The increment in glucose oxidation was similar to that which may have been expected from the amino acid-induced increase in plasma insulin (33). This observation indicates that amino acids do not exert major effects on glucose oxidation in healthy humans. Similar observations have been made in obese nondiabetic patients and in obese NIDDM patients (34). Altogether, the data available indicate that amino acids have major effects on glucose production (to be discussed later) but do not interfere with insulinmediated glucose uptake and oxidation. This absence of interactions can be explained by the fact that the major oxidative pathways used for most amino acids is their conversion to glucose prior to oxidation of the neoformed glucose (35). Branched chain amino acids, however, differ from this general scheme in that they are quantitatively oxidized directly in muscle where they compete with glucose.

\section{Effect of other substrates on glucose utilization and glucose production}

Ethanol is ingested in significant amounts by many individuals occasionally or as part of their every day diet. Moreover, it has been reported that severe ethanol intoxication may be responsible for the development of acute reversible forms of diabetes (36). It has been proposed that ethanol-induced inhibition of insulin secretion is the mechanism at the origin of diabetes in this setting. In addition, acute ethanol administration can decrease whole body glucose utilization, oxidation and storage in healthy volunteers studied during 
euglycemic, hyperinsulinemic clamps (37). The mechanisms by which ethanol induces insulin resistance remain unclear. Ethanol is essentially metabolized in liver cells whereas the major portion of glucose oxidation and storage takes place in skeletal muscle. It is therefore unlikely that alterations of glucose metabolism are direct consequences of ethanol on insulinsensitive tissues. A substantial portion of ethanol is subsequently oxidized as acetate in both insulininsensitive and insulin-sensitive tissues. Infusions of acetate, however, do not reduce insulin-mediated glucose utilization, indicating that ethanol-induced insulin resistance does not result from substrate competition in the strict sense of the term (38). A possible explanation for ethanol-induced insulin resistance is activation of muscle sympathetic nerve activity which occurs following acute ethanol administration (39). Indeed, it has been observed that stimulation of sympathetic activity attained by application of lower body negative pressure decreases insulin sensitivity by mechanisms which remain to be determined $(40,41)$.

The effects of various endogenous intermediary substrates on insulin-mediated glucose disposal have also been assessed in healthy subjects. Ketone body administration did not reduce insulin-mediated glucose utilization (42). Although glucose oxidation was not measured under these conditions, it is likely that ketone bodies were essentially oxidized and that such oxidation took place in insulin-sensitive tissues, at least to some extent. Lactate administration also failed to decrease insulin-mediated glucose disposal although it did reduce glucose oxidation during hyperinsulinemia (43). These observations stress the fact that the inhibition of glucose oxidation observed during administration of lipids does not account for the decrease in glucose transport and glycogen synthesis, and that specific features of lipid metabolism, as yet unidentified, are involved in this inhibition.

\section{Effects of nutrients on endogenous glucose production}

Apart from altering insulin-mediated glucose uptake and metabolism in skeletal muscle and adipose tissue, macro nutrients or their intermediary substrates may also alter glucose homeostasis by modulating glucose production in liver and kidney cells (Fig. 3). As already mentioned, infusion of a mixture of amino acids during glucose or glucose plus insulin infusion (hyperinsulinemic euglycemic clamp) led to significant increases in endogenous glucose production. This stimulation of endogenous glucose production was completely inhibited when hyperglucagonemia was prevented by somatostatin plus basal glucagon replacement; it was however restored during infusions of somatostatin plus high glucagon infusion (producing plasma glucagon concentrations of about $250 \mathrm{mg} / \mathrm{ml}$ ). This indicates that amino acid-induced hyperglucagonemia was responsible for

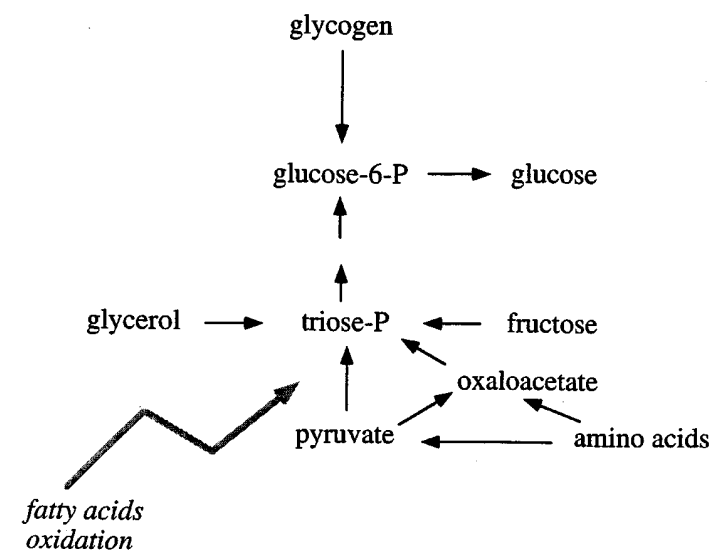

Figure 3 Endogenous glucose production results from a combination of two processes: glycogenolysis and gluconeogenesis. The latter can be modulated by varying the supply of exogenous or endogenous gluconeogenic precursors (amino acids, glycerol, fructose ...). In addition, an increased supply of fatty acids stimulates gluconeogenesis, presumably by providing NADH and ATP.

stimulation of glucose production (30). Apart from proteins, other macronutrients also stimulate gluconeogenesis. Metabolism of triglycerides leads to the formation of glycerol which is, to a large extent, converted into glucose in liver and kidney cells (7). Administration of labeled glycerol in quantitative amounts led to the appearance of labeled glucose in the plasma, demonstrating that gluconeogenesis was a major pathway of glycerol metabolism $(44,45)$. Overall, however, glucose production did not increase. Similar observations were made during infusions of lactate $(46,47)$.

Fructose is a naturally occurring sugar which represents, on average, $10 \%$ of our energy intake. It is essentially metabolized in liver cells to fructose-1phosphate and triose-phosphates. A substantial portion of the triose-phosphates formed from fructose are subsequently reconverted into glucose by the gluconeogenic pathway. Administration of ${ }^{13} \mathrm{C}$-labeled fructose, whether orally or intravenously, has been shown to yield large amounts of ${ }^{13} \mathrm{C}$-labeled glucose in the plasma, indicating a marked stimulation of gluconeogenesis (48). Here again, overall endogenous glucose production failed to increase unless hyperglucagonemia was superimposed. This suggests that, under normal euglucagonemic conditions, there is an autoregulation of glucose production which prevents net glucose output from increasing when gluconeogenesis is stimulated. In contrast, fructose did induce an increase in glucose production during experimental hyperglucagonemia obtained by infusion of exogenous glucagon (49). This further stresses the role of glucagon in the stimulation of endogenous glucose production induced by amino acids.

Although fatty acids cannot be converted to glucose in humans to any significant extent, fatty acid 
metabolism at the level of liver cells nonetheless modulates glucose production in liver cells. In isolated hepatocytes, fatty acids stimulate gluconeogenesis from a variety of substrates, an effect which has been attributed to increased ATP formation and NADH provision during fatty acid oxidation. These effects of lipid substrates have also been observed in vivo in humans. Infusion of a triglyceride emulsion stimulated gluconeogenesis from lactate in healthy volunteers (50). However, as observed during infusion of gluconeogenic substrates, such a stimulation of gluconeogenesis failed to stimulate endogenous glucose production.

\section{Conclusions and perspectives}

Proteins, lipids and ethanol all interact to some extent with glucose metabolism. Lipids decrease glucose oxidation in tissues in which glucose transport is insulin-dependent whereas amino acids (with the exception of branched chain amino acids) do not appear to compete directly with glucose in these tissues. They are, however, largely metabolized to glucose prior to oxidation and therefore replace, in a net sense, endogenous or dietary carbohydrates. Amino acids (both endogenous and dietary) and glycerol, formed from triglyceride hydrolysis, stimulate gluconeogenesis by providing gluconeogenic precursors. Free fatty acids also indirectly stimulate gluconeogenesis, presumably by providing the energy required to sustain this process. Only amino acids, however, stimulate total glucose production, due to amino acid-induced glucagon secretion. Other gluconeogenic substrates fail to enhance glucose production, due to an autoregulation which prevents an increase in glucose output. Of all substrates which interact with glucose metabolism, fatty acids represent a special case. Increased fatty acid availability decreases not only glucose oxidation, but glucose transport and glycogen synthesis as well, through mechanisms which remain unknown. Free fatty acids also seem to occupy a special place in the control of endogenous glucose production. Although infusion of lipid emulsions fail to alter endogenous glucose production in the postabsorptive state, recent data indicate that insulin-induced suppression of lipolysis and free fatty acid concentrations participate in the suppression of endogenous glucose production observed after a meal (51).

The role of increased availability of lipids and amino acids on glucose metabolism in obese and NIDDM patients remains poorly understood. It appears likely that increased fatty acid oxidation interferes with insulin action in both normal and obese individuals; its contribution to hepatic and intrahepatic insulin resistance remains, however, to be specified. In addition, it remains unknown whether neuroendocrine anomalies which eventually develop in obese and/or NIDDM patients may alter the effects of gluconeogenic substrates on endogenous glucose production.

\section{References}

1 Gerich JE. Control of glycaemia. Baillières Clinical Endocrinology and Metabolism 19937 551-586.

2 Gay LJ, Schneiter P, Schutz Y, Di Vetta V, Jéquier E \& Tappy L. A non invasive assessment of hepatic glycogen kinetics and postabsorptive gluconeogenesis in man. Diabetologia 199437 517523.

3 Magnusson I, Rothman DL, Katz LD, Shulman RG \& Shulman GI. Increased rate of gluconeogenesis in type II diabetes mellitus. A ${ }^{13} \mathrm{C}$ nuclear magnetic resonance study. Journal of Clinical Investigation 199290 1323-1327.

4 Felber JP, Acheson KJ \& Tappy L (Eds). From Obesity to Diabetes. Chichester: John Wiley \& Sons, 1992.

5 Jahoor F, Herndon DN \& Wolfe RR. Role of insulin and glucagon in the response of glucose and alanine kinetics in burn-injured patients. Journal of Clinical Investigation 198678 807-814.

6 Jahoor F, Peters EJ \& Wolfe RR. The relationship between gluconeogenic substrate supply and glucose production in humans. American Journal of Physiology 1990258 E288-E296.

7 Jahoor F, Klein S \& Wolfe R. Mechanism of regulation of glucose production by lipolysis in humans. American Journal of Physiology 1992262 E353-E358.

8 Welle S, Barnard RR, Statt M \& Amatruda JM. Increased protein turnover in obese women. Metabolism 199241 1028-1034.

9 Randle P, Garland P, Hales C \& Newsholme E. The glucose fattyacid cycle. Its role in insulin sensitivity and the metabolic disturbances of diabetes mellitus. Lancet 1963 i 785-789.

10 Gomez F, Jéquier E, Chabot V, Buber V \& Felber JP. Carbohydrate and lipid oxidation in normal human subjects: its influence on glucose tolerance and insulin response to glucose. Metabolism $197221381-391$.

11 Ferrannini E, Barrett EJ, Bevilacqua S \& DeFronzo RA. Effect of fatty acids on glucose production and utilization in man. Journal of Clinical Investigation 198372 1737-1747.

12 Thiébaud D, DeFronzo RA, Jacot E, Golay A, Acheson K, Maeder E et al. Effect of long-chain triglyceride infusion on glucose metabolism in man. Metabolism 198231 1128-1136.

13 Roden M, Price TB, Perseghin G, Petersen KF, Rothman DL, Cline GW et al. Mechanism of free fatty acid-induced insulin resistance in humans. Journal of Clinical Investigation 199697 2859-2865.

14 Nuutila P, Koivisto VA, Knuuti J, Ruotsalainen U, Teräs M, Haaparanta M et al. Glucose-free fatty acid cycle operates in human heart and skeletal muscle in vivo. Journal of Clinical Investigation 199289 1767-1774.

15 Boden G. Role of fatty acids in the pathogenesis of insulin resistance and NIDDM. Diabetes 199746 3-10.

16 Boden G, Chen X, Ruiz J, White JV \& Rossetti L. Mechanisms of fatty acid-induced inhibition of glucose uptake. Journal of Clinical Investigation $1994932438-2446$.

17 Kelley DE, Mokan M, Simoneau JA \& Mandarino LJ. Interaction between glucose and free fatty acid metabolism in human skeletal muscle. Journal of Clinical Investigation 199392 91-98.

18 Boden G, Jadali F, White J, Liang Y, Mozzoli M, Chen X et al. Effects of fat on insulin-stimulated carbohydrate metabolism in normal man. Journal of Clinical Investigation 199188 960966.

19 Meylan M, Henny C, Temler E, Jéquier E \& Felber J. Metabolic factors in the insulin resistance in human obesity. Metabolism $198736256-261$.

20 Felley C, Felley E, Van Melle G, Frascarolo P, Jéquier E \& Felber J. Impairment of glucose disposal by infusion of triglycerides in humans: role of glycemia. American Journal of Physiology 1989 256 E747-E752. 
21 Boden G \& Chen X. Effects of fat on glucose uptake and utilization in patients with non-insulin-dependent diabetes. Journal of Clinica Investigation 199596 1261-1268.

22 Tappy L, Randin D, Vollenweider P, Vollenweider L, Paquot N, Scherrer U et al. Mechanisms of dexamethasone-induced insulin resistance in healthy humans. Journal of Clinical Endocrinology and Metabolism 199479 1063-1069.

23 Fulcher GR, Walker M, Farrer M, Johnson AS \& Alberti KGMM Acipimox increases glucose disposal in normal man independent of changes in plasma nonesterified fatty acid concentration and whole-body lipid oxidation rate. Metabolism 199342 308-314.

24 Peeters RA \& Veerkamp JH. Does fatty acid-binding protein play a role in fatty acid transport? Molecular and Cellular Biochemistry $19898845-49$.

25 Hotamisligil GS, Johnson RS, Distel RJ, Ellis REP \& Spiegelman BM. Uncoupling of obesity from insulin resistance through a targeted mutation in aP2, the adipocyte fatty acid binding protein. Science 1996274 1377-1379.

26 Hotamisligil GS, Peraldi P \& Spiegelman BM. The molecular link between obesity and diabetes. Current Opinion in Endocrinology and Diabetes 19963 16-23.

27 Schwenk WF \& Haymond MW. Decreased uptake of glucose by human forearm during infusion of leucine, isoleucine, or threonine. Diabetes 198736 199-204.

28 Tessari P, Inchiostro S, Biolo G, Duner E, Nosadini R, Tiengo A et al. Hyperaminoacidaemia reduces insulin-mediated glucose disposal in healthy men. Diabetologia 198528 870-872.

29 Boden G \& Tappy L. Effects of amino acids on glucose disposal. Diabetes 199039 1079-1084.

30 Boden G, Tappy L, Jadali F, Hoeldtke RD, Rezvani I \& Owen OE Role of glucagon in disposal of an amino acid load. American Journal of Physiology 1990259 E225-E232.

31 Ferrannini E, Bevilacqua S, Bonadonna R, Giorico MA, Boni C \& Ciociaro D. Metabolic interactions between glucose and amino acids in man. Diabetologia 198629 36A.

32 Tappy L, Paquot N, Tounian P, Schneiter P \& Jéquier E. Assessment of glucose metabolism in humans with the simultaneous use of indirect calorimetry and tracer techniques. Clinical Physiology $1995151-12$.

33 Tappy L, Acheson K, Normand S, Schneeberger D, Thélin A, Pachiaudi C et al. Effects of infused amino acids on glucose production and utilization in healthy human subjects. American Journal of Physiology 1992262 E826-E833.

34 Tappy L, Acheson K, Normand S, Pachiaudi C, Jéquier E \& Riou JP. Effects of glucose and amino acid infusion on glucose turnover in insulin-resistant obese and type II diabetic patients. Metabolism $199443428-434$

35 Jungas RL, Halperin ML \& Brosnan JT. Quantitative analysis of amino acid oxidation and related gluconeogenesis in humans. Physiology Review 199272 419-448.

36 Phillips GB \& Safrit HF. Alcoholic diabetes. Induction of glucose intolerance with alcohol. Journal of the American Medical Association 1971217 1513-1519.

37 Shelmet JJ, Reichard GA, Skutches CL, Hoeldtke RD, Owen OE \& Boden G. Ethanol causes acute inhibition of carbohydrate, fat, and protein oxidation and insulin resistance. Journal of Clinical Investigation 198881 1137-1145.
38 Yki-Järvinen H, Koivisto VA, Ylikahri R \& Taskinen MR. Acute effects of ethanol and acetate on glucose kinetics in normal subjects. American Journal of Physiology 1988254 E175E180.

39 Randin D, Vollenweider P, Tappy L, Jéquier E, Nicod P \& Scherrer U. Suppression of alcohol-induced hypertension by dexamethasone. New England Journal of Medicine 1995332 1733-1737.

40 Lembo G, Capaldo B, Rendina V, Iaccarino G, Napoli R, Guida R et al. Acute noradrenergic activation induces insulin resistance in human skeletal muscle. American Journal of Physiology 1994266 E242-E247.

41 Tappy L, Girardet K, Schwaller N, Vollenweider L, Jéquier E, Nicod P et al. Metabolic effects of an increase of sympathetic activity in healthy humans. International Journal of Obesity 1995 19 419-422.

42 Bratusch-Marrain PR \& DeFronzo RA. Failure of hyperketonemia to alter basal and insulin-mediated glucose metabolism in man. Hormones and Metabolic Research 198618 185-189.

43 Paquot N, Schneiter P, Cayeux MC, Chioléro R, Temler E, Jéquier E et al. Effects of infused sodium lactate on glucose and energy metabolism in healthy humans. Diabetes and Metabolism 199521 345-352.

44 Winkler B, Rathgeb I, Steele R \& Altszuler N. Conversion of glycerol to glucose in the normal dog. American Journal of Physiology 1970219 497-502.

45 Winkler B, Rathgeb I, Bjerknes C, Steele R \& Altszuler N. Effect of norepinephrine on glycerol and glucose metabolism in the normal dog. American Journal of Physiology 1973225 81-84.

46 Jenssen T, Nurjhan N, Consoli A \& Gerich JE. Failure of substrateinduced gluconeogenesis to increase overall glucose appearance in normal humans. Journal of Clinical Investigation 199086 489497.

47 Haesler E, Schneiter P, Temler E, Jéquier E \& Tappy L. Effects of lactate infusion on hepatic gluconeogenesis and glycogenolysis. Clinical Physiology 199515 581-595.

48 Tounian P, Schneiter P, Henry S, Jéquier E \& Tappy L. Effects of infused fructose on endogenous glucose production, gluconeogenesis and glycogen metabolism in healthy humans. American Journal of Physiology 1994267 E710-E717.

49 Paquot N, Schneiter P, Jéquier E, Gaillard R, Lefèbvre PJ, Scheen A et al. Effects of ingested fructose and infused glucagon on endogenous glucose production in obese NIDDM patients, obese non-diabetic subjects, and healthy subjects. Diabetologia 199639 580-586.

50 Clore JN, Glickman PS, Nestler JE \& Blackard WG. In vivo evidence for hepatic autoregulation during FFA-stimulated gluconeogenesis in normal humans. American Journal of Physiology 1991261 E425-E429.

51 Rebrin K, Steil GM, Mittelman SD \& Bergman RN. Causal linkage between insulin suppression of lipolysis and suppression of liver glucose output in dogs. Journal of Clinical Investigation 199698 741-749.

Received 28 May 1997

Accepted 26 August 1997 